\title{
CIHR to simplify open-funding programs
}

$\mathrm{T}$

he Canadian Institutes of Health Research (CIHR) is overhauling the grant programs under its open-funding envelope to encourage more "off-the-wall" research and to simplify the process of writing and reviewing grant applications.

"Our system truly wasn't working," says Dr. Jane Aubin, chief scientific officer at CIHR. "The workloads for applicants, the complexity of our programs and the burden on peer reviewers were all felt to be unsustainable."

The agency will reorganize its existing suite of 12 grant programs into two broad funding streams: short-term project grants for research with a specific goal, and long-term foundation grants for researchers with records of excellence.

CIHR will also scrap its committeebased peer-review structure, which involved groups of researchers meeting together to discuss applications. Instead, it's launching a web-based process to match grant applications to individual reviewers for remote vetting.

Some scientists believe the research community's fundamental problem is lack of resources. With many researchers competing for limited funds, grant applicants are more likely to play it safe in the projects they pitch than to pursue ambitious work, says Philippe Gros, a CIHR distinguished investigator and professor of biochemistry at McGill University in Montréal, Quebec. "It creates a very high application pressure to deal with."

Gros is also worried about the isolation involved in web-based peer review. "Personally, I would like more of a hybrid system in which you could have a web-based review with a much more structured role for panels," he says.

CIHR will try to achieve that balance by maintaining a small number of committees whose members will meet during the final stages of peer review "to refocus on the applications that really need additional discussion," says Aubin.

Others contend that remote peer review will result in fairer funding decisions by removing the influence of other committee members from individual reviewers' judgments. The current system "where each committee has its own cul-

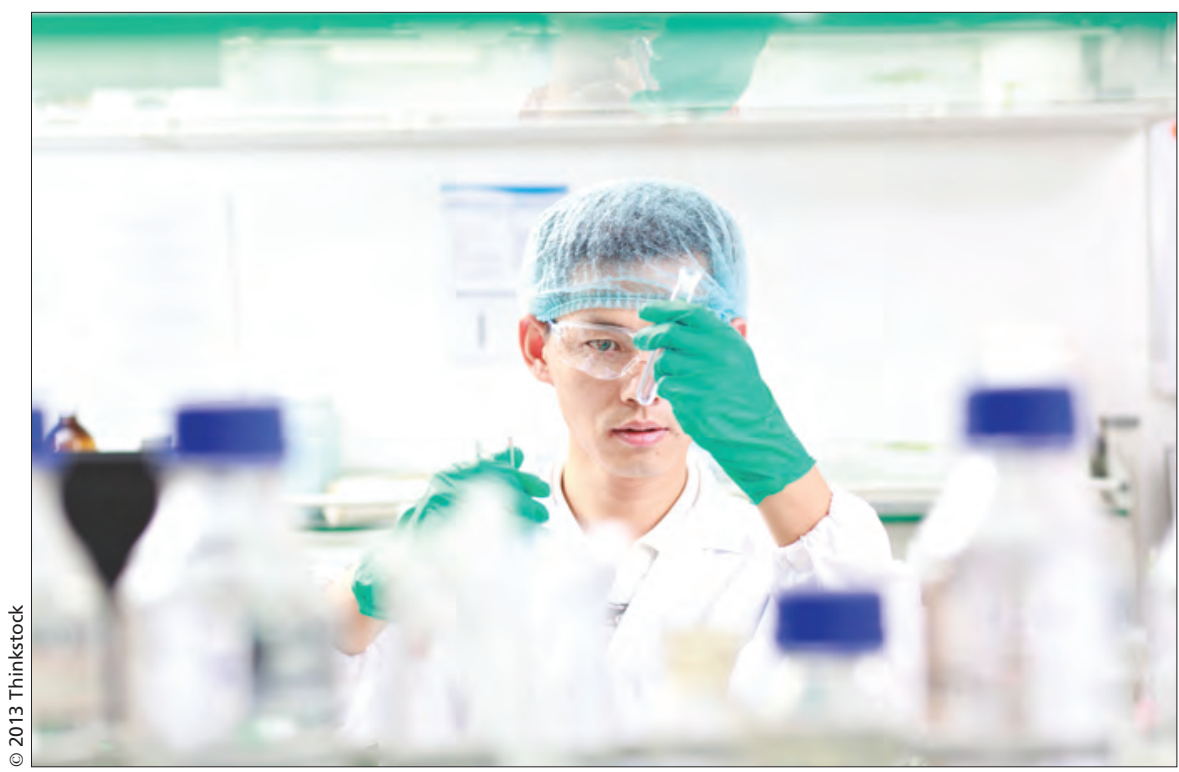

$\mathrm{CIHR}$ is overhauling the grant programs under its open-funding envelope to encourage more "off-the-wall" research and to simplify its grant application process.

ture" and potential biases "has significant problems, including penalizing ambitious science and those trying to push the boundaries," Brett Finlay, a CIHR distinguished investigator and professor of biochemistry and molecular biology at the University of British Columbia in Vancouver, writes in an email.

CIHR has also found it increasingly difficult to populate enough review committees to keep up with the evolution of science, says Aubin.

The switch to remote peer review means CIHR can now match every application to multiple peer reviewers with the most appropriate expertise, without requiring them to attend committee meetings in Ottawa, Ontario, she explains. "You can also fish more outside Canada, because quite frankly ... we get turned down by a lot [of international reviewers] because they can't afford the time to spend a day and a half [travelling] to Canada and back."

The reforms encourage more "novel, completely exciting, off-the-wall" research by providing longer funding windows to leading researchers through the new foundation track, says Aubin. Established investigators will receive up to seven years of funding, while new investigators can receive five years.

"Within those five to seven years, we're asking researchers to do the most exciting, innovative research they can dream of so they don't have to come back and convince peer reviewers again and again."

Though many researchers and peer reviewers have embraced the simplicity of the two funding streams, says Aubin, some question changing the peerreview process at the same time.

"There is insufficient evidence that [the reforms] will produce higher quality review of grant proposals than the current system, and the proposed pilot experiments will not evaluate peer review quality over the timeframes that are currently proposed," Philip Hieter, director of the Michael Smith Laboratories at the University of British Columbia, writes in an email. Hieter wants CIHR to delay the peer review changes until they are evaluated.

Given that $45 \%$ of CIHR's open-funding envelope will be distributed to $25 \%$ of the principal investigators through foundation grants, "the need for high-quality review is even more important," he wrote.

CIHR will launch the first foundation grant competition in fall 2014, and the first project grant competition in spring 2014. — Lauren Vogel, CMAJ 